\section{Periodontal conditions and associated factors among adults and the elderly: findings from the first National Oral Health Survey in Uruguay}

\author{
Enfermedad periodontal y factores asociados \\ en la población adulta y adulta mayor: primer \\ Relevamiento Nacional de Salud Bucal en Uruguay
}

\author{
A doença periodontal e fatores associados entre \\ adultos e idosos: dados da Pesquisa Nacional de \\ Saúde Bucal no Uruguai
}

Susana M. Lorenzo ${ }^{1}$
Ramón Alvarez 1
Ernesto Andrade 1
Virginia Piccardo ${ }^{1}$
Alejandro Francia 1
Fernando Massa 2
Marcos Britto Correa 3
Marco Aurélio Peres ${ }^{4}$

\section{Resumen}

El objetivo del estudio fue conocer la prevalencia de enfermedad periodontal en la población adulta y anciana uruguaya y su asociación con factores comportamentales y socioeconómicos. Se utilizaron datos de adultos (35-44, $n=358$ ) $y$ ancianos $(65-74, n=411)$ participantes en el primer Relevamiento Nacional de Salud Bucal en Uruguay. El relevamiento incluyó un cuestionario sobre factores de riesgo, incluyendo tabaco. Sangrado al sondaje bolsa periodontal (IPC) y pérdida de inserción (PIP) fueron valorados mediante examen clínico. Considerando las dos edades, la prevalencia de enfermedad moderada/severa fue de 21,8\% y 9,12\% para severa. En el análisis multivariado, se observó asociación entre nivel universitario de educación y todas las variables de respuesta. La asistencia odontológica estuvo negativamente asociada con la enfermedad periodontal moderada a severa. La prevalencia fue mayor en el grupo con menor nivel socioeconómico. En los ancianos, el hábito de fumar estuvo fuertemente asociado con la enfermedad periodontal.

Enfermedades Periodontales; Encuestas de Salud Bucal; Adulto; Anciano
Periodontal Diseases; Dental Health Surveys; Adult; Aged 


\section{Introduction}

Periodontal diseases are one of the most important oral health conditions affecting populations around the world. These are a major cause of tooth loss, particularly among the elderly, and significantly impact the quality of life of individuals, representing a public health problem 1 .

There are different manifestations of plaqueinduced periodontal diseases and these can vary from initial stages such as plaque-induced gingival disease to more severe conditions such as periodontitis 2 . The understanding of the distribution and factors associated with these conditions can provide useful information in planning public health actions 3 . For all of these reasons, epidemiological analysis of data provided by nationwide surveys is a crucial tool for better distribution of financial and available human resources.

The prevalence of the periodontal conditions varies significantly between ages and countries. In Europe, epidemiological evidence indicates that mild gingival inflammation and mild to moderate loss of periodontal attachment in specific sites are prevalent in the adult population but epidemiological studies available from most Eastern European countries are limited 4,5. Data from the 2009-2010 National Health and $\mathrm{Nu}$ trition Examination Survey (NHANES) revealed that the prevalence of periodontitis in the adult population (35-49 years) was $36.6 \%$ while in the elderly it was $70.1 \% 6$. In this context, little data is available for Latin America 7; considering the last Brazilian national survey performed in 2010, the prevalence of bleeding on probing in middle-age adults was $45.8 \%$ and in older adults $18.1 \%$. For periodontal disease, the prevalence of "moderate to severe" symptoms in adults, ranged from $15.3 \%$ to $5.8 \%$ for "severe" 8 .

Considering associated factors, such as other chronic diseases, periodontal conditions share both systemic and local determinants 9. The common risk factor approach (CRFA) considers that oral diseases, such as periodontal diseases, share common factors with systemic non-communicable diseases and this approach allows for more efficient public health planning 10,11. As for systemic factors, some findings suggest that patients with type I and II diabetes, obesity and stress are more prone to presenting periodontal diseases $12,13,14,15,16$. In addition, behavioral variables, such as tobacco use, dietary and hygiene habits are also associated with this condition $17,18,19$. Finally, there is also a strong relationship between socioeconomic factors and periodontal conditions, where an important social gradient can be found 20,21 .
In the case of Uruguay, a recent National Oral Health Survey was carried out in the adult population in 2010-2011. Preliminary analyses revealed that for the population living in the countryside the prevalence of bleeding and of shallow periodontal pockets was 36.1 and $28.5 \%$, respectively 22,23 . However, comprehensive data for the whole population, considering provinces and the capital, for different age ranges and factors associated with the different periodontal conditions, are not available. Therefore, the aims of this study are to assess the prevalence of periodontal outcomes in the Uruguayan adult population and investigate its association with demographic, socioeconomic and behavioral characteristics.

\section{Methods}

This cross-sectional study is part of the first $\mathrm{Na}$ tional Oral Health Survey in the young and adult population of Uruguay. Uruguay is a South American country situated between Argentina and Brazil, with an area of $176,215 \mathrm{~km}^{2}$ and a population of 3,334,052 inhabitants (Instituto Nacional de Estadística. Censo 2011. http://www.ine.gub. uy/censos2011/index.html, accessed on 09/ Jan/2015). Its economy is based on agriculture and services.

The survey was performed in the context of the implementation of the Uruguayan National Health System, following World Health Organization (WHO) guidelines for oral health surveys 8,24. A stratified, double phase cluster sampling design was adopted. In fact, we used the sample design of the National Statistics Institute which took into account socioeconomic positions. This was the first sampling phase of the study. The sample calculation was performed in order to obtain representative sub-samples by region (capital and the provinces) and age groups: 15-24, 35-44, 65-74 years. The National Statistics Institute randomly selected the sample. The capital and the rest of the provinces were considered in two independent samples: one for the provinces ( $\mathrm{n}=1,503$ : 715 - 15-24 years; $394-35-44$ years; $394-65$ 74 years) and another for the capital ( $\mathrm{n}=1,503$ : 715 - 15-24 years; 394 - 35-44 years; $394-65-74$ years). The total number for the sample considered the two most prevalent diseases: caries and periodontal conditions. For the calculation of the sample size, a prevalence of dental caries of $85 \%$ was considered for both middle aged and older adults. For young adults, the outcome used was the prevalence of periodontal disease of $54 \%$. The calculation also took into consideration a type I error of $5 \%$, a power of $80 \%$ and a design effect of 1.5 and added $20 \%$ for non-responses. According 
to these calculations, the total number expected for the sample corresponding to adults and elderly was 1,576 individuals: 788 for each age group (394 for the countryside and 394 for Montevideo in each age group). In order to achieve this sample size, four waves corresponding to continuous household survey information 22 were used. The continuous household survey is a multistage stratified cluster survey where the final sampling units are the households. This survey is conducted every two months. The latter is considered the first sampling phase.

In the second phase, four waves of the survey were used to select the minimum necessary to achieve the calculated sample size for each age group. We have a total of 4,000 people, of which 1,430 belonged to the age group of 15-24, the remaining 2,500 belonged to adults and elderly. Therefore, the required 1,576 were selected by simple random sampling.

The study was performed in 2010-2011 and comprised a clinical examination that included several oral conditions (caries, periodontal diseases, malocclusions and mucosal lesions) and a questionnaire with socio-demographic, socioeconomic and behavioral variables. A post calibration process of the sample was carried out to compensate for age and gender imbalances. More details about the methods of this population-based study are available elsewhere 22 .

\section{Outcomes}

Periodontal outcomes were assessed based on the modified Community Periodontal Index (CPI) 24. Clinical evaluation was performed in all sextants using the CPI probe. In each sextant, the index teeth were probed in six sites (mesio-bucal, midbuccal, disto-buccal, disto-lingual, mid-lingual and mesio-lingual). Bleeding on probing (BOP) was assessed in all sextants and then the individuals categorized in "present "or "absent" for both conditions. Presence of periodontal pockets was measured as the distance from the free gingival margin to the bottom of the gingival sulcus and individuals were classified using the following categorization: "absent", when the pocket depth was from 0 to $3 \mathrm{~mm}$ and; "present" when the pocket depth was $\geq 4 \mathrm{~mm}$. Individuals with absence of teeth in all sextants were considered as "missing". The Brazilian national oral health survey modification for CPI was used. It consisted of measuring all periodontal conditions (BOP, calculus, periodontal pockets and clinical attachment loss - CAL) in each index tooth and reporting the value for each condition, not only the worst situation by sextant as the original CPI index does. CAL was also performed in all sextants using the following categories: (0) up to $3 \mathrm{~mm}$; (1) 4-5mm; (2) 6-8mm; (3) 9-11mm and; (4) $12 \mathrm{~mm}$ or more (Instituto Nacional de Estadística. Censo 2011. http://www.ine.gub.uy/censos2011/index. html, accessed on 09/Jan/2015). Outcomes were analyzed considering two variables: CAL and CPI. Periodontal disease was defined as: (i) moderate to severe when CPI $>2$ (periodontal pocket $\geq 4 \mathrm{~mm}$ ) and CAL $>0$ (CAL $\geq 4 \mathrm{~mm}$ ) and; (ii) severe when CPI $>2$ (periodontal pocket $\geq 4 \mathrm{~mm}$ ) and $\mathrm{CAL}>1(\mathrm{CAL} \geq 6)$. Although $\mathrm{CPI}>2$ was used as the cut-off point, $\mathrm{CPI}=5$ (excluded sextants) was not included because neither the cause of the tooth loss nor the status of the possible remaining tooth in the sextant were known.

\section{Independent variables}

The following independent variables were considered: sex, age, region and socioeconomic status, health service coverage, time since the last dental visit, smoking habits and tooth brushing frequency.

Age was noted in years and then categorized in the following groups: 35-44, 65-74 years. Region of the country was considered as "capital", for Montevideo inhabitants, and provinces for other regions. The presence of at least one person with a university degree in the household (yes/no) was used as a socioeconomic categorical variable.

Type of health service used was assessed by the question: "Which type of health service do you attend when you feel sick?" and then categorized as public or private. In Uruguay the Health Care System integrates both public and private sectors. Economically this resembles an insurance system where the working population is requested to pay an amount proportional to their incomes while the State is responsible for the payments of unemployed people. All the gathered financial resources are distributed between public and private providers according to the composition of the covered population, depending on age and sex. Users have the possibility of choosing between the public and private sectors whereby in the private sector most services should be paid for and there is no free of charge dental care for adults and the elderly, while in the public sector all health care benefits are free of charge for the users.

Time since the last dental visit was assessed in months and categorized in "up to 12 months", "more than 12 months" and "never visited".

Toothbrushing frequency was determined using the following options: never, once a month, twice or three times/month, once a week, twice to six times/week, once a day and twice or more/ 
day. This variable was then dichotomized in "twice or more/day" and "less than twice a day".

Smoking habits were assessed by asking if currently, the individual smokes daily and the number of cigarettes per day. Then the variable was categorized in three groups: does not smoke/ smokes but not daily, smokes up to 10 cigarettes/ day and smokes more than 10 cigarettes/day.

\section{Fieldwork}

The fieldwork team was comprised of six dentists assisted by dental students from the University of the Republic School of Dentistry. All examinations were performed at the individual's home. Participants were examined sitting under artificial illumination (a head lamp). The examiners were properly dressed, and all safety and biohazard measures were adopted. CPI probes and buccal mirrors were used to conduct the dental examination.

All examiners and interviewers were trained and calibrated by a researcher with experience in this type of epidemiological study. Two calibration processes were performed during the fieldwork and 40 individuals were examined in each opportunity to ensure the inter-examiner reliability. The Brazilian National Oral Health Survey methodology was used 25 . The calibration process consisted of a twofold process: firstly a theoretical phase where all diagnostic criteria were discussed and secondly a practical phase where 40 individuals were dentally examined twice, in order to calculate intra and inter examiner reliability indexes. For the inter examiner reliability calculation a gold standard examination was obtained in consensus between the examiners and the instructor. This consensus method consisted of a discussion after all examinations, of the discrepancies among the findings of the examiners in each participant. Inter-examiner reliabilities were calculated using weighted and simple kappa tests when appropriate. For periodontal pocket conditions, the values vary from 0.6 to 1 (mean value $=0.74$ in the first calibration and 0.90 in the second). Intra examiner values vary from 0.67 to 0.98 .

\section{Statistical analysis}

Data analysis was performed using Stata 11.2 (StataCorp LP, College Station, USA). All analyses considered the study design and sample weight of the survey, employing the svy. commands complex data samples. Distribution of periodontal outcomes (BOP, mild to severe periodontal disease and severe periodontal disease) by independent variables was assessed by descriptive analysis and bivariate analyses were performed using the Rao Scott test. Multivariate analysis was performed using Poisson regression models for the three outcomes which allowed the estimation of the prevalence ratio (PR) and respective 95\% confidence intervals $(95 \% \mathrm{CI})$. A hierarchical approach was used in the multivariate analysis. For this purpose, independent variables were divided in two blocks in order to determine their entrance in the models. The first block comprised demographic and socioeconomic variables and the second block included behavioral characteristics. Variables from block 1 were adjusted by the variables of the same block. Block 2 variables were adjusted by block 1 and block 2 variables. To remain in each phase of the analysis (block 1 and full model) variables had to present a $\mathrm{p}$-value $\leq$ 0.250 . A stepwise backward selection procedure was performed in each phase of the model. Multivariate analyses were also performed stratified by age groups (adults and elderly).

\section{Ethical aspects}

The study protocol was approved by the University of the Republic School of Dentistry Ethics Research Committee. All participants provided written informed consent and people were informed about their health status and directed to the nearest health center.

\section{Results}

The total sample comprised 769 individuals: 484 for the countryside: 225 - 35-44 years; 259 - 65-74 years and 285 for the capital: 133 - 35-44 years; $152-65-74$ years. The response rate was $51.2 \%$.

The response rate was higher in Montevideo (74.8\%) and among women (77\%). The worst response rate was in Canelones province (33\%). From the total sample, $358(61.6 \%)$ were from the 35-44 age group and 411 (38.4\%) were from the 65-74 age group. Regarding demographic variables, $50.6 \%$ of the participants were women and $49.8 \%$ were from the capital (Montevideo).

Considering adults and the elderly, the prevalence of BOP was $40.8 \%$ (CI95\%: 35.9-46.0), 21.8\% (17.9-26.3) for the mild/severe periodontal disease and $9.12 \%(6.8-12.1)$ for the severe periodontal disease case. Nearly $1 / 6$ of participants had all sextants excluded due to missing teeth ( $2 \%$ of adults and $35 \%$ of elderly). The population with at least one excluded sextant was $51.4 \%$ (45.0-57.8) for the adult population and $86.4 \%$ (81.0-90.4) of the elderly, respectively.

The distribution of outcomes by independent variables is displayed in Table 1. Males presented 
Distribution of periodontal conditions according to independent variables in Uruguayan adult and elderly populations: unadjusted, bivariate analysis.

\begin{tabular}{|c|c|c|c|}
\hline \multirow[t]{3}{*}{ Independent variable } & \multirow{3}{*}{$\begin{array}{c}\text { BOP }(n=604) \\
\%(95 \% \mathrm{Cl})\end{array}$} & \multicolumn{2}{|c|}{ Periodontal disease moderate/severe } \\
\hline & & Moderate/Severe $(n=612)$ & Severe $(n=612)$ \\
\hline & & $\%(95 \% \mathrm{Cl})$ & $\%(95 \% \mathrm{Cl})$ \\
\hline \multicolumn{4}{|l|}{ Block 1} \\
\hline \multicolumn{4}{|l|}{ Sex } \\
\hline Female & 35.6 * (29.7-42.0) & $12.9^{\star \star}(9.7-17.0)$ & $6.5 *(4.5-9.4)$ \\
\hline Male & $45.9 *(38.1-53.9)$ & 30.1 ** $(23.8-38.2)$ & $11.7 *(7.8-17.2)$ \\
\hline \multicolumn{4}{|l|}{ Region } \\
\hline Provinces & $37.3(31.2-43.8)$ & $23.3(18.3-29.2)$ & $11.2 * *(8.1-15.1)$ \\
\hline Capital & $43.8(36.3-51.4)$ & $20.6(15.2-27.4)$ & $7.5 * \star(4.4-12.4)$ \\
\hline \multicolumn{4}{|l|}{ Age group (years) } \\
\hline $35-44$ & $43.8(36.9-49.8)$ & $16.5^{\star \star}(12.1-22.0)$ & $5.9(3.6-9.5)$ \\
\hline $65-74$ & $35.0(28.2-42.5)$ & $34.7^{\star \star}(27.7-42.4)$ & $17.0(12.1-23.2)$ \\
\hline \multicolumn{4}{|l|}{ University degree } \\
\hline Yes & 30.6 ** $(22.6-39.8)$ & $14.8 *(9.7-21.9)$ & $3.9 * \star(2.1-7.2)$ \\
\hline No & $46.0 * \star(40.0-52.2)$ & 25.6 * (20.5-31.4) & $11.8 * \star(8.5-16.1)$ \\
\hline \multicolumn{4}{|l|}{ Block 2} \\
\hline \multicolumn{4}{|l|}{ Type of health services } \\
\hline Private & 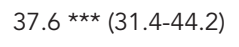 & $21.4(16.5-27.4)$ & $8.8(6.0-12.6)$ \\
\hline Public & $46.7^{\star \star \star}(38.6-66.1)$ & $22.2(16.4-29.3)$ & $9.9(6.2-15.6)$ \\
\hline \multicolumn{4}{|l|}{ Time since last dental visit } \\
\hline Up to 12 months & $34.0 *(26.9-41.8)$ & 18.4 ** $(13.1-25.2)$ & $7.3(4.4-11.9)$ \\
\hline More than 12 months & $46.9 *(40.1-53.8)$ & 24.6 ** (19.2-30.9) & $10.9(7.6-15.5)$ \\
\hline Never used dental services & $90.3 *(46.1-99.0)$ & 94.6 ** $(0.6-99.5)$ & $25.3(4.4-71.3)$ \\
\hline \multicolumn{4}{|l|}{ Tooth brushing } \\
\hline$\geq$ twice a day & 36.1 * (30.8-41.9) & $17.9 * *(14.0-22.7)$ & $8.1(5.7-11.4)$ \\
\hline$<$ twice a day & $57.1 *(45.8-67.7)$ & 35.1 ** (25.4-46.2) & $12.5(7.2-20.9)$ \\
\hline \multicolumn{4}{|l|}{ Tobacco use } \\
\hline Do not smoke/not daily & $39.3(33.8-44.9)$ & $20.6(16.3-25.7)$ & $8.6(6.0-12.1)$ \\
\hline Up to 10 cigarettes/day & $54.5(32.9-74.4)$ & $23.5(11.6-41.7)$ & $9.3(2.6-28.1)$ \\
\hline More than 10 cigarretes/day & $44.8(31.6-58.8)$ & $27.7(17.6-41.7)$ & $11.9(6.7-20.4)$ \\
\hline
\end{tabular}

95\% Cl: $95 \%$ confidence interval; BOP: bleeding on probing.

* p-value $\leq 5 \%$;

** p-value $\leq 1 \%$;

$* \star *$-value $\leq 10 \%$.

a higher prevalence of all periodontal outcomes compared with females. The prevalence of moderate to severe periodontal disease was higher in the elderly than in adults. The presence of a university degree in the household presented lower levels of all periodontal conditions (BOP, moderate to severe and severe periodontal disease). In addition, people who live in the provinces have a greater prevalence of severe periodontal disease than those living in the capital. The time since the last dental visit was also associated with BOP and periodontal disease (moderate/severe). People that have never used dental services presented a higher prevalence of BOP and mild/severe periodontitis. The prevalence of BOP and moderate/severe periodontal disease was also higher in people who reported brushing their teeth less than twice a day. In bivariate analysis, smoking habits were not associated with any periodontal conditions (neither moderate/severe nor severe periodontitis).

Adjusted analyses showed that individuals who live without a person with a university degree in the household presented a greater pre- 
valence of all the outcomes, having almost three times greater the prevalence of severe periodontitis compared with those living with a person with a high level of education. In addition, people who had never used dental services in their life presented a greater prevalence of BOP and moderate/severe periodontitis compared with those who have visited the dentist in the last 12 months (Table 2).

Tables 3 and 4 illustrate the results of multivariate analyses of periodontal outcomes, stratified by age groups. The results for adults are displayed in Table 3. In this age group, males presented a prevalence of mild to severe periodontal disease that was almost three times higher than females.
In addition, participants who did not have a person with a university degree in the household presented the highest prevalence rate for all three evaluated outcomes.

Adjusted analysis in the elderly population revealed that the use of tobacco was associated with all outcomes. People who reported smoking more than 10 cigarettes per day presented a prevalence almost twice as large of BOP and mild/ severe periodontitis compared with those who reported not smoking or not smoking daily. In addition, the prevalence of severe periodontitis was more than three times higher in the heavy smoker group than in those who do not smoke or do not smoke daily (Table 4 ).

Table 2

Association between periodontal conditions and independent variables in adults and elderly in Uruguay: multivariate poisson regression analysis.

\begin{tabular}{|c|c|c|c|c|c|c|c|c|c|}
\hline \multirow[t]{3}{*}{ Independent variables } & \multicolumn{3}{|c|}{$\mathrm{BOP}(\mathrm{n}=588)$} & \multicolumn{6}{|c|}{ Periodontal disease } \\
\hline & \multirow[b]{2}{*}{ PR $_{\text {adjusted }}$} & \multirow[b]{2}{*}{$95 \% \mathrm{Cl}$} & \multirow[b]{2}{*}{ p-value } & \multicolumn{3}{|c|}{ Moderate/severe $(n=599)$} & \multicolumn{3}{|c|}{ Severe $(n=599)$} \\
\hline & & & & $\mathrm{PR}_{\text {adjusted }}$ & $95 \% \mathrm{Cl}$ & $\mathrm{p}$-value & $\mathrm{PR}_{\text {adjusted }}$ & $95 \% \mathrm{Cl}$ & $\mathrm{p}$-value \\
\hline \multicolumn{10}{|l|}{ Block 1} \\
\hline Sex & & & 0.077 & & & $<0.001$ & & & 0.065 \\
\hline Female & 1.00 & & & 1.00 & & & 1.00 & & \\
\hline Male & 1.24 & $0.98-1.59$ & & 2.25 & $1.57-3.23$ & & 2.00 & $1.03-2.93$ & \\
\hline Region & & & 0.120 & & & & & & \\
\hline Provinces & 1.00 & & & & & & 1.00 & & \\
\hline Capital & 1.20 & $0.95-1.54$ & & & & & 0.68 & $0.37-1.23$ & \\
\hline Age group (years) & & & 0.092 & & & $<0.001$ & & & $<0.001$ \\
\hline $35-44$ & 1.00 & & & 1.00 & & & 1.00 & & \\
\hline $65-74$ & 0.81 & $0.63-1.04$ & & 2.09 & $1.47-2.98$ & & 2.97 & $1.66-5.29$ & \\
\hline University & & & 0.010 & & & 0.018 & & & $<0.001$ \\
\hline Yes & 1.00 & & & 1.00 & & & 1.00 & & \\
\hline No & 1.51 & $1.10-2.07$ & & 1.71 & $1.10-2.67$ & & 2.93 & $1.49-5.77$ & \\
\hline \multicolumn{10}{|l|}{ Block 2} \\
\hline Type of health services & & & 0.236 & & & & & & \\
\hline Private & 1.00 & & & & & & & & \\
\hline Public & 1.07 & $0.84-1.37$ & & & & & & & \\
\hline Time since last dental visit & & & 0.001 & & & 0.032 & & & 0.583 \\
\hline Up to 12 months & 1.00 & & & 1.00 & & & 1.00 & & \\
\hline 12 or more months & 1.30 & $1.00-1.68$ & & 1.10 & $0.75-1.61$ & & 1.16 & $0.91-2.86$ & \\
\hline $\begin{array}{l}\text { Never used dental } \\
\text { services }\end{array}$ & 2.00 & $1.35-2.98$ & & 2.63 & $1.29-5.38$ & & 1.54 & $1.37-6.14$ & \\
\hline Tooth brushing & & & 0.024 & & & 0.156 & & & 0.895 \\
\hline$\geq$ twice a day & 1.00 & & & 1.00 & & & 1.00 & & \\
\hline$<$ twice a day & 1.37 & $1.04-1.79$ & & 1.37 & $0.89-2.10$ & & 1.03 & $0.54-1.95$ & \\
\hline Tobacco use & & & 0.980 & & & 0.550 & & & 0.392 \\
\hline Do not smoke /not daily & 1.00 & & & 1.00 & & & 1.00 & & \\
\hline Up to 10 cigarettes/day & 1.30 & $0.84-2.25$ & & 1.10 & $0.57-2.10$ & & 1.05 & $0.26-4.24$ & \\
\hline 10 or more cigarretes/day & 1.00 & $0.71-1.42$ & & 1.33 & $0.81-2.16$ & & 1.65 & $0.79-3.44$ & \\
\hline
\end{tabular}

95\% Cl: 95\% confidence interval; BOP: bleeding on probing; PR: prevalence ratio. 
Association between periodontal conditions and independent variables in adult population (aged 35-44 years) in Uruguay: multivariate poisson regression analysis.

\begin{tabular}{|c|c|c|c|c|c|c|c|c|c|}
\hline \multirow[t]{3}{*}{ Independent variables } & \multicolumn{3}{|c|}{ BOP $(n=338)$} & \multicolumn{6}{|c|}{ Periodontal disease } \\
\hline & \multirow[b]{2}{*}{$\mathbf{P R}_{\text {adjusted }}$} & \multirow[b]{2}{*}{$95 \% \mathrm{Cl}$} & \multirow[b]{2}{*}{ p-value } & \multicolumn{3}{|c|}{ Moderate/severe $(n=347)$} & \multicolumn{3}{|c|}{ Severe $(n=347)$} \\
\hline & & & & $\mathrm{PR}_{\text {adjusted }}$ & $95 \% \mathrm{Cl}$ & $\mathrm{p}$-value & $\mathbf{P R}_{\text {adjusted }}$ & $95 \% \mathrm{Cl}$ & $\mathrm{p}$-value \\
\hline \multicolumn{10}{|l|}{ Block 1} \\
\hline Sex & & & 0.180 & & & $<0.001$ & & & 0.192 \\
\hline Female & 1.00 & & & 1.00 & & & 1.00 & & \\
\hline Male & 1.22 & $0.93-1.68$ & & 2.93 & $1.64-5.25$ & & 1.82 & $0.71-4.62$ & \\
\hline Region & & & 0.060 & & & & & & \\
\hline Provinces & 1.00 & & & & & & & & \\
\hline Capital & 1.32 & $0.94-1.69$ & & & & & & & \\
\hline University & & & 0.026 & & & 0.060 & & & 0.007 \\
\hline Yes & 1.00 & & & 1.00 & & & 1.00 & & \\
\hline No & 1.57 & $0.86-1.60$ & & 2.22 & $0.98-5.03$ & & 7.93 & $1.76-35.8$ & \\
\hline \multicolumn{10}{|l|}{ Block 2} \\
\hline Type of health services & & & 0.331 & & & & & & 0.336 \\
\hline Private & 1.00 & & & & & & 1.00 & & \\
\hline Public & 1.16 & $0.86-1.56$ & & & & & 1.41 & $0.56-5.54$ & \\
\hline Time since last dental visit & & & 0.002 & & & & & & \\
\hline Up to 12 months & 1.00 & & & & & & & & \\
\hline 12 or more months & 1.19 & $0.88-1.61$ & & & & & & & \\
\hline Never used dental services & 1.88 & $1.32-2.67$ & & & & & & & \\
\hline Tooth brushing & & & 0.087 & & & 0.111 & & & \\
\hline$\geq$ twice a day & 1.00 & & & 1.00 & & & & & \\
\hline$<$ twice a day & 1.35 & $0.96-1.90$ & & 1.71 & $0.89-3.30$ & & & & \\
\hline Tobacco use & & & 0.761 & & & 0.780 & & & 0.687 \\
\hline Do not smoke/not daily & 1.00 & & & 1.00 & & & 1.00 & & \\
\hline Up to 10 cigarettes/day & 1.15 & $0.65-2.04$ & & 1.28 & $0.55-2.98$ & & 1.68 & $0.41-6.91$ & \\
\hline 10 or more cigarretes/day & 0.90 & $0.61-1.34$ & & 1.21 & $0.61-2.37$ & & 0.87 & $0.28-2.69$ & \\
\hline
\end{tabular}

95\% Cl: 95\% confidence interval; BOP: bleeding on probing; PR: prevalence ratio.

\section{Discussion}

This was the first population-based study that assessed periodontal conditions in the adult and elderly population of Uruguay. The response rate obtained could be considered a weakness; however, in order to address this limitation, a calibration process was performed in the sample to allow the sex and age range to be kept proportional to the Uruguayan population 22.

Despite the relatively high non-response rate, a post-calibration process of the sample was carried out in order to compensate the initial different proportion between gender and ages. The post-calibration process consisted in adjusting sample weights according to the Uruguayan population when considering age and gender. This procedure makes our findings of fundamental importance to planning oral health strategies in the context of the new national health system implemented recently by the Uruguayan government 27 . Associations should be interpreted with caution due to the cross-sectional design used in this survey. As a Stata statistic program was used, we applied a specific test to analyze associations (Rao Scott) that considered sample weights and inflated these weights. Some associations could not have been detected due to the sample size which impacted negatively on the power to detect differences between groups. In fact, the sample size design was planned to calculate prevalence rather than to estimate differences. In the elderly, the stratification by age in the data analysis allows us to detect some differences between heavy daily smokers and people who do not smoke or smoke only a few cigarettes. The worst 
Association between periodontal conditions and independent variables in the elderly (aged 65-74 years) in Uruguay: multivariate poisson regression analysis.

\begin{tabular}{|c|c|c|c|c|c|c|c|c|c|}
\hline \multirow[t]{3}{*}{ Independent variables } & \multirow{2}{*}{\multicolumn{3}{|c|}{$\mathrm{BOP}(n=250)$}} & \multicolumn{6}{|c|}{ Periodontal disease } \\
\hline & & & & \multicolumn{3}{|c|}{ Moderate/severe $(n=265)$} & \multicolumn{3}{|c|}{ Severe $(n=265)$} \\
\hline & $\mathrm{PR}_{\text {adjusted }}$ & $95 \% \mathrm{Cl}$ & $\mathrm{p}$-value & PR $R_{\text {adjusted }}$ & $95 \% \mathrm{Cl}$ & $\mathrm{p}$-value & PR adjusted & $95 \% \mathrm{Cl}$ & $\mathrm{p}$-value \\
\hline \multicolumn{10}{|l|}{ Block 1} \\
\hline Sex & & & 0.153 & & & 0.012 & & & 0.110 \\
\hline Female & 1.00 & & & 1.00 & & & 1.00 & & \\
\hline Male & 1.33 & $0.98-1.83$ & & 1.69 & $1.12-2.56$ & & 1.64 & $0.89-3.30$ & \\
\hline Region & & & 0.690 & & & 0.220 & & & 0.115 \\
\hline Provinces & 1.00 & & & 1.00 & & & 1.00 & & \\
\hline Capital & 0.92 & $0.62-1.37$ & & 1.35 & $0.83-2.19$ & & 0.57 & $0.29-1.15$ & \\
\hline University & & & 0.166 & & & 0.925 & & & 0.093 \\
\hline Yes & 1.00 & & & 1.00 & & & 1.00 & & \\
\hline No & 1.38 & $0.87-2.20$ & & 0.98 & $0.66-1.46$ & & 1.90 & $0.90-4.03$ & \\
\hline \multicolumn{10}{|l|}{ Block 2} \\
\hline Type of health services & & & 0.408 & & & & & & \\
\hline Private & 1.00 & & & & & & & & \\
\hline Public & 0.82 & $0.53-1.29$ & & & & & & & \\
\hline Time since last dental visit & & & 0.128 & & & 0.806 & & & 0.618 \\
\hline Up to 12 months & 1.00 & & & 1.00 & & & 1.00 & & \\
\hline 12 or more months & 1.66 & $1.02-2.72$ & & 1.04 & $0.67-1.63$ & & 0.79 & $0.43-1.46$ & \\
\hline Never used dental services & 1.61 & $0.59-5.01$ & & 1.44 & $0.70-2.97$ & & 1.10 & $0.47-2.56$ & \\
\hline Tooth brushing & & & 0.231 & & & 0.624 & & & \\
\hline$\geq$ twice a day & 1.00 & & & 1.00 & & & 1.00 & & \\
\hline$<$ twice a day & 1.28 & $0.86-1.90$ & & 1.11 & $0.79-1.75$ & & 1.05 & $0.57-1.95$ & \\
\hline Tobacco use & & & 0.016 & & & 0.009 & & & $<0.001$ \\
\hline Do not smoke /not daily & 1.00 & & & 1.00 & & & 1.00 & & \\
\hline Up to 10 cigarettes/day & 1.72 & $1.05-2.83$ & & 0.72 & $0.20-2.59$ & & 3.58 & $1.36-1.94$ & \\
\hline 10 or more cigarretes/day & 1.81 & $1.16-2.83$ & & 1.92 & $1.25-2.97$ & & 3.59 & $1.84-7.00$ & \\
\hline
\end{tabular}

95\% Cl: 95\% confidence interval; BOP: bleeding on probing; PR: prevalence ratio.

situation was in adults because the non- response rate was higher than in the elderly group. The population-based sample could be considered an important strength, allowing the extrapolation of the present findings (prevalence) to the whole country. In addition, the calibration process of examiners confers reliability to our results and complex statistical procedures have improved the external validity of our study.

Another limitation for our study was found: the use of CPI index 24 has important limitations such as the underestimation of prevalence of periodontal conditions due to the use of index teeth 27,28 . However, CPI is widely used around the world, conferring comparability to our results between countries. In addition, the fact that the CPI index was modified and national Brazilian oral health survey criteria were used allows us to measure each periodontal condition separately and not only the worst condition, as is expected using the original CPI index. On the other hand, the combination of probing depth and clinical attachment loss as well as the use of two cutoff points to determine periodontal disease can all be highlighted as an effort to obtain detailed information about the periodontal status of the studied population.

CAL was not calibrated in this study in the same way as in the Brazilian national survey and this can be considered a limitation of our study.

The prevalence of periodontal outcomes was similar to those found in South American countries bordering Uruguay ${ }^{3}$. In comparison with the most recent national study performed in Brazil in 2010 (SBBrasil 2010) ${ }^{29}$ which used the same methodological approach, the results of periodontal conditions found in Uruguay were very similar to conditions observed in Brazil. On the 
other hand, prevalence of BOP was significantly higher in the Uruguayan population. The adult population in Uruguay also has more excluded sextants than in Brazil. This fact could be related to the absence of oral health care coverage for this age group in Uruguay.

Gender differences were found in the presence of periodontal disease. Males presented worse periodontal conditions, corroborating with previous findings 8,19 . This association can be explained by the fact that females tend not only to have better health behaviors but are also more likely in the long term to maintain oral health beliefs and smoke less 21 . An increase in the prevalence of periodontal disease was also observed in the elderly in comparison with adults. This is expected due to the chronic characteristics of periodontal disease and corroborates with previous studies 6 .

The influence of socioeconomic gradients in general and oral health outcomes as well as in periodontal conditions 1,3,6,11,18 are well established in the literature. In the present study, the presence of a person with a university degree in the household was used as a socioeconomic indicator. Although the individual level of schooling would provide more sensitive information, this data was not available for the studied population. Education is a strong determinant of employment and income 30 , so it is expected that the socioeconomic status of families with at least one member with a university degree should be higher in comparison with those without people with completed university studies.

The effect of socioeconomic status on periodontal disease can be explained using largely complementary theoretical frameworks. Material resources can improve nutrition and the ability to afford oral care products. Another way to explain this effect can be through the immunosuppressive effect of stress in response to social determinants. Psychosocial stress caused by poverty, unemployment and poor living conditions negatively affect health 10 . Stress can alter the inflammatory mediators and defense cells leading to periodontal disease. Also, psychological factors can affect behaviors associated with periodontal conditions, such as oral health behaviors and tobacco use. All these factors are affected by contextual factors, such as social structure and environment, which act as upstream influences that shape individual and proximal conditions affecting periodontitis 21 .

The fact that the presence of a person with a university degree in the household was found to be associated with periodontal disease in adults but not in the elderly could be due to the difference in the proportion of excluded sextants between the adults and the elderly. Periodontal disease outcomes may be associated with the proportion of excluded sextants and the latter with socioeconomic status. As the proportion of excluded sextants may be greater among individuals who do not have a person with a university degree in the household, there may be fewer individuals to evaluate with the CPI index (more than two teeth should be present for the sextant to be considered).

Considering the presence of at least one person with a university degree in the household, our data are in concordance with national figures. Using the Centro de Investigaciones Económicas (CINVE) report 31 , the proportion of households with a person with a university degree varies from $20 \%$ to $37 \%$, according to the socioeconomic level: medium-upper and high-inferior, respectively. The mean values for all the population are similar in our study (30\%).

With respect to smoking habits in the elderly, heavy smokers presented more periodontal disease (moderate and severe) than those who reported that they did not smoke or did not smoke daily. There is a lot of evidence showing the effects of tobacco use on periodontal health $9,20,32$. Dose-dependent association between smoking and periodontitis using the number of cigarettes smoked per day is well documented in the literature 9,33. It is important to mention that data from the first Uruguayan survey of risk factors for chronic diseases showed that nearly one third of the Uruguayan adult population have daily smoking habits, being more prevalent in males than in females. These figures coincide with our findings in the adult population. However, we do not have the possibility to compare with elderly smokers because the age groups that were considered in both surveys are different (55-64 years: risk factors survey) ${ }^{34}$.

Strategies focused on the reduction of tobacco use are under way in Uruguay. It has been the first country to adopt a national program of tobacco use. In addition, a reduction in the number of smokers is expected for the next years, which may reduce the risk for development of several chronic conditions, including periodontal disease.

People who visited the dentist in the last year had better gingival conditions than those who did not. Other studies describe the relationship between visiting the dentist and periodontal conditions 6,17 . This finding is related to the fact that these people are more concerned about their oral health and in better positions to take care of it. On the other hand, people who attend health services and manage to obtain oral health treatment are probably those with a better socio- 
economic status and this factor was also associated with worse periodontal condition in adults. An aspect that should be analyzed is the reduced offer of public oral health care for the adult and elderly populations in Uruguay, which is focused on emergency demands only. The high prevalence of outcomes in people who have never used a dental service draws attention to the need for the establishment of policies focused on oral health in the context of the Uruguayan National Health Service.

Previous data about the periodontal status of the Uruguayan population were included in a recent review about the global burden of periodontal diseases 3 . However, it is important to highlight that this previous study was carried out in the 1980s in a non-representative sample of Uruguay, including only the individuals from the capital, and did not include older adults, which makes the comparison of the findings and the extrapolation of this data difficult.

To conclude, it could be stated that considering the prevalence of periodontal outcomes, a global national program promoting oral health that includes the prevention and treatment needs of periodontal conditions should be implemented. It might be integrated into national general health programmes of non-communicable diseases. It should also include the population approach using common risk factor approach (CRFA) and some group risk actions according to socioeconomic satatus and regional differences. This will contribute towards addressing health inequalities and save financial resources in the context of national health.

\section{Resumo}

O objetivo do estudo foi determinar a prevalência da doença periodontal em adultos e idosos uruguaios e sua associação com fatores comportamentais e socioeconômicos. Foram utilizados dados de adultos (35-44, $n=358)$ e de idosos $(65-74, n=411)$ participantes da primeira Pesquisa Nacional de Saúde Bucal, no Uruguai, em 2011. A pesquisa incluiu um questionário sobre fatores de risco, incluindo fumo. Sangramento ao sandagem bolsa periodontal (IPC) e perda de inserção (PIP) foram avaliados por meio de exame clínico. Considerando-se as duas idades, a prevalência da doença moderada/grave foi de 21,8\% e 9,12\%. Na análise multivariada, foi observada associação entre a educação de nível universitário e todas as variáveis de resposta. $O$ atendimento odontológico foi negativamente associado com a doença periodontal moderada e grave. A prevalência foi maior no grupo com menor nível socioeconômico. Dentre os idosos, o tabagismo foi fortemente associado à doença periodontal.

Doenças Periodontais; Inquéritos de Saúde Bucal; Adulto; Idoso

\section{Contributors}

S. M. Lorenzo participated on the design and planning of the study, analysis and interpretation of the results, coordination of fieldwork and wrote-up the article. R. Alvarez contributed on the design of the study, analysis and interpretation of data, revision and approval of final version. E. Andrade participated on the writing of article and approved the final version. V. Piccardo and A. Francia collaborated on data collection and write-up the article. F. Massa paticipated on the design and planning of the study, data analysis, revision and approval of final version. M. B. Correa participated on the training of the fieldwork team, analysis and interpretation of results, and wrote-up and revised the article. M. A. Peres contributed on the planning of the study, analysis and interpretation of data, wrote the the article and revised the final version.

\section{Acknowledgments}

We would like to thank the support of the University Commission for Scientific Research (CSIC) of the University of the Republic, who was the main sponsor of this survey and the School of Dentristry of the University and the Uruguayan Society of Dental Research (SUIO) for the partial funding of this project. 


\section{References}

1. Petersen PE, Baehni PC. Periodontal health and global public health. Periodontol 2000 2012; 60: 7-14.

2. Armitage GC. Periodontal diagnoses and classification of periodontal diseases. Periodontol 2000 2004; 34:9-21.

3. Petersen PE, Ogawa H. The global burden of periodontal disease: towards integration with chronic disease prevention and control. Periodontol 2000 2012; 60:15-39.

4. Sheiham A, Netuveli GS. Periodontal diseases in Europe. Periodontol 2000 2002; 29:104-21.

5. Hermann P, Gera I, Borbely J, Fejerdy P, Madlena M. Periodontal health of an adult population in Hungary: findings of a national survey. J Clin Periodontol 2009; 36:449-57.

6. Thornton-Evans G, Eke P, Wei L, Palmer A, Moeti R, Hutchins S, et al. Periodontitis among adults aged $\geq 30$ years - United States, 2009-2010. MMWR Surveill Summ 2013; 62 Suppl 3:129-35.

7. Oppermann RV, Haas AN, Rösing CK, Susin C. Epidemiology of periodontal diseases in adults from Latin America. Periodontol 2000 2015; 67:13-33.

8. Vettore MV, Marques RAA, Peres MA. Desigualdades sociais e doença periodontal no estudo SBBrasil 2010: abordagem multinível. Rev Saúde Pública 2013; 47 Suppl 3:29-39.

9. Genco RJ, Borgnakke WS. Risk factors for periodontal disease. Periodontol 2000 2013; 62:59-94.

10. Watt RG. Social determinants of oral health inequalities: implications for action. Community Dent Oral Epidemiol 2012; 40 Suppl 2:44-8.

11. Sheiham A, Watt RG. The common risk factor approach: a rational basis for promoting oral health. Community Dent Oral Epidemiol 2000; 28: 399-406.

12. García Ramos FE, Solís Villanueva J, Calderón Ticona JR, Luque Cuba EJ, Neyra Arismendiz LA, Manrique Hurtado HA, et al. Prevalencia de diabetes mellitus y factores de riesgo relacionados en una población urbana. Rev Soc Peru Med Interna 2007; 20:90-4.

13. Boland MR, Hripcsak G, Albers DJ, Wei Y, Wilcox $\mathrm{AB}$, Wei J, et al. Discovering medical conditions associated with periodontitis using linked electronic health records. J Clin Periodontol 2013; 40:474-82.

14. Morita I, Inagaki K, Nakamura F, Noguchi T, Matsubara T, Yoshii S, et al. Relationship between periodontal status and levels of glycated hemoglobin. J Dent Res 2012; 91:161-6.

15. Demmer RT, Jacobs DR, Desvarieux M. Periodontal disease and incident type 2 diabetes: results from the first National Health and Nutrition Examination Survey and its epidemiologic follow-up study. Diabetes Care 2008; 31:1373-9.

16. Lalla E, Park DB, Papapanou PN, Lamster IB. Oral disease burden in northern Manhattan patients with diabetes mellitus. Am J Public Health 2004; 94:755-8.
17. Klein BEK, Klein R, Knudtson MD. Life-style correlates of tooth loss in an adult Midwestern population. J Public Health Dent 2004; 64:145-50.

18. Frias AC, Antunes JLF, Fratucci MVB, Zilbovicius C, Junqueira SR, Souza SF, et al. Estudo de base populacional sobre as condições periodontais e determinantes socioeconômicos em adultos residentes no município de Guarulhos (SP), Brasil, 2006. Rev Bras Epidemiol 2011; 14:495-507.

19. Bastos JL, Boing AF, Peres KG, Antunes JLF, Peres MA. Periodontal outcomes and social, racial and gender inequalities in Brazil: a systematic review of the literature between 1999 and 2008. Cad Saúde Pública 2011; 27 Suppl 2:S141-53.

20. Klinge B, Norlund A. A socio-economic perspective on periodontal diseases: a systematic review. J Clin Periodontol 2005; 32 Suppl 6:314-25.

21. Thomson WM, Sheiham A, Spencer AJ. Sociobehavioral aspects of periodontal disease. Periodontol 2000 2012; 60:54-63.

22. Lorenzo S, Alvarez R Blanco S, Peres M. Primer Relevamiento Nacional de Salud Bucal en poblacion joven y adulta uruguaya 2010-2011: aspectos metodológicos. Odontoestomatol 2013; 15:8-25.

23. Lorenzo S, Piccardo V, Alvarez F, Massa F, Alavarez R. Enfermedad periodontal en la población joven y adulta uruguaya del interior del país. Relevamiento Nacional 2010-2011. Odontoestomatol 2013; 15(n.spe):35-46.

24. Organización Mundial de la Salud. Encuestas de salud bucodental: métodos básicos. 4ạ Ed. Geneva: Organización Mundial de la Salud; 1997.

25. Área Técnica de Saúde Bucal, Departamento de Atenção Básica, Secretaria Políticas de Saúde, Ministério da Saúde. Projeto SB2000: condições de saúde bucal da população brasileira no ano 2000: manual do examinador. Brasília: Ministério da Saúde; 2001. (Série C. Projetos, Programas e Relatórios, 53).

26. Cámara de Representantes de la República Oriental del Uruguay. Ley n. 18.211. Sistema Nacional Integrado de Salud: normativa referente a su creación, funcionamiento y financiación. Diario Oficial 2007; 13 dic.

27. Kingman A, Albandar JM. Methodological aspects of epidemiological studies of periodontal diseases. Periodontol 2000 2002; 29:11-30.

28. Peres MA, Peres KG, Cascaes AM, Correa MB, Demarco FF, Hallal PC, et al. Validity of partial protocols to assess the prevalence of periodontal outcomes and associated sociodemographic and behavior factors in adolescents and young adults. J Periodontol 2012; 83:369-78.

29. Coordenação Geral de Saúde Bucal, Departamento de Atenção Básica, Secretaria de Atenção à Saúde, Ministério da Saúde. Projeto SB Brasil 2010: pesquisa nacional de saúde bucal - resultados principais. Brasília: Ministério da Saúde; 2011. 
30. Galobardes B, Shaw M, Lawlor DA, Lynch JW, Smith GD. Indicators of socioeconomic position (part 1). J Epidemiol Community Health 2006; 60:7-12.

31. Llambí C, Piñeyro L. Indice de nivel socioeconómicos (INSE). http://www.gruporadar.com.uy/01/ wp-content/uploads/2012/04/Informe-NuevoINSE-2011.pdf (accessed on 21/May/2014).

32. Enwonwu CO, Salako N. The periodontal diseasesystemic health-infectious disease axis in developing countries. Periodontol 2000 2012; 60:64-77.
33. Lu H-X, Wong MCM, Lo ECM, McGrath C. Risk indicators of oral health status among young adults aged 18 years analyzed by negative binomial regression. BMC Oral Health 2013; 13:40.

34. División de Epidemiología, Dirección General de la Salud, Ministerio de Salud Pública. 1a Encuesta Nacional de Factores de Riesgo de Enfermedades Crónicas no Transmisibles. http://www.msp.gub. uy/sites/default/files/archivos_adjuntos/1er_en frecnt_2006_1.pdf (accessed on 21/May/2014).

Submitted on $29 / \mathrm{Jan} / 2015$

Final version resubmitted on 21/May/2015 Approved on 03/Jun/2015 